\title{
Numerical Studies of the Effects of Water Capsules on Self-Healing Efficiency and Mechanical Properties in Cementitious Materials
}

\author{
Haoliang Huang ${ }^{1}$ and Guang $\mathrm{Ye}^{2}$ \\ ${ }^{1}$ School of Materials Science and Engineering, Southeast University, Nanjing 211189, China \\ ${ }^{2}$ Microlab, Faculty of Civil Engineering and Geoscience, Delft University of Technology, 2628 CN Delft, Netherlands \\ Correspondence should be addressed to Haoliang Huang; h.l.huang@msn.com
}

Received 12 March 2016; Revised 18 July 2016; Accepted 19 July 2016

Academic Editor: Joao M. L. Reis

Copyright (c) 2016 H. Huang and G. Ye. This is an open access article distributed under the Creative Commons Attribution License, which permits unrestricted use, distribution, and reproduction in any medium, provided the original work is properly cited.

\begin{abstract}
In this research, self-healing due to further hydration of unhydrated cement particles is taken as an example for investigating the effects of capsules on the self-healing efficiency and mechanical properties of cementitious materials. The efficiency of supply of water by using capsules as a function of capsule dosages and sizes was determined numerically. By knowing the amount of water supplied via capsules, the efficiency of self-healing due to further hydration of unhydrated cement was quantified. In addition, the impact of capsules on mechanical properties was investigated numerically. The amount of released water increases with the dosage of capsules at different slops as the size of capsules varies. Concerning the best efficiency of self-healing, the optimizing size of capsules is $6.5 \mathrm{~mm}$ for capsule dosages of $3 \%, 5 \%$, and $7 \%$, respectively. Both elastic modulus and tensile strength of cementitious materials decrease with the increase of capsule. The decreasing tendency of tensile strength is larger than that of elastic modulus. However, it was found that the increase of positive effect (the capacity of inducing self-healing) of capsules is larger than that of negative effects (decreasing mechanical properties) when the dosage of capsules increases.
\end{abstract}

\section{Introduction}

Cracking, caused by shrinkage and external loadings, is inherent in reinforced concrete structures. The cracks in reinforced concrete structures facilitate the ingress of aggressive agents and reduce service life of concrete structures. Manmade repair is a traditional solution for the aforementioned problem. However, it is recognized that man-made repair can not last for a long time [1]. Moreover, the cracks in concrete under water or underground are usually inaccessible for man-made repair. Compared to man-made repair, selfhealing of cracks, defined as autonomous repairs of cracks [2], can be beneficial [3-6]. Self-healing of cracks has attracted much attention in recent years [7-10]. For instance, capsules storing various adhesive agents are being manufactured in laboratory for self-healing of cracks in cementitious materials [11-13]. Mineral admixtures are used to develop self-healing concrete as well [14-19]. Bacteria are also applied as selfhealing agent in concrete structures [17, 20-24]. Even without these aforementioned healing agents, cementitious materials have the ability of self-healing, that is, autogenous selfhealing [7, 25-28]. It has been reported that the availability of water is essential for autogenous self-healing and selfhealing based on mineral admixtures and bacteria $[9,10]$. Therefore, it is necessary to supply water into cracks in order to promote self-healing based on these mechanisms in concrete structures when concrete structures serve in a dry environment. To do this, water can be stored in capsules and then added into concrete. However, the efficiency of water supply via capsules and its effect on self-healing capacity are insufficiently studied. The impacts of capsules on mechanical properties of cementitious materials as a function of capsule dosages are still unclear either.

In this research, self-healing due to further hydration of unhydrated cement particles is taken as an example for investigating the effects of capsules on the self-healing efficiency and mechanical properties of cementitious materials. It is well known that a substantial amount of cement 
remains unhydrated over time due to the lack of water, especially in high performance concrete, as shown in Figure 1 [29]. To promote further hydration, extra water is stored in capsules which are premixed in matrix. When cement matrix cracks, some capsules are broken and the water stored in the capsules is released into the cracks. Thus, further hydration of unhydrated cement particles is promoted. The cracks are expected to be healed by the products of further hydration which are formed in the cracks.

Previous studies $[12,23,30]$ have shown that the capsules storing liquid healing agents can be strong enough to resist forces during mixing of concrete but weak enough to be easily broken when hit by cracks. In this study, it was supposed that such capsules can be used to store water. In order to evaluate the feasibility of self-healing by using water capsules, the efficiency of supply of water by using capsules as a function of capsule dosages and sizes will be determined numerically. By knowing the amount of water supplied via capsules, the efficiency of self-healing due to further hydration of unhydrated cement can be quantified by modeling. In addition, the impact of capsules on mechanical properties is also investigated numerically.

\section{Reviews of Self-Healing Efficiency versus the Amount of Released Water}

In order to determine the efficiency of self-healing due to further hydration of unhydrated cement as a function of capsule dosage and size, the relationship between the selfhealing efficiency and the amount of released water should be determined first. This relationship had been investigated in previous study [31]. It was reviewed in this section in order to provide a clearer image of this paper.

\subsection{Mechanism of Self-Healing by Further Hydration. As} shown in Figure 2, the encapsuled water is embedded in concrete matrix. Because of the low strength of capsules, the capsules are assumed to be broken when they are hit by cracks. The water stored in capsules is released immediately and the cracks are filled with water. When the unhydrated cement particles on the crack surfaces contact with water, the clinker phases of unhydrated cement dissolve instantly. $\mathrm{Ca}^{2+}$ begins to diffuse out from unhydrated cement particles immediately and then the silicate starts to diffuse out as well [31]. Consequently, the concentrations of various ions in the crack solution increase gradually. Once the concentrations of ions reach the equilibrium criteria for the precipitation, the further hydration products are formed in the crack. Along with the further hydration products formed around the unhydrated cement, the rate of further hydration slows down and gradually becomes more and more diffusioncontrolled $[34,35]$. During this period, some parts of the ions are consumed to form the hydration products while other parts of ions may diffuse into the crack solution. Therefore, the formation of healing products in the crack keeps going on but becomes slower and slower.

In addition to the unhydrated cement exposed on the crack surfaces, some ions also diffuse into the solution in

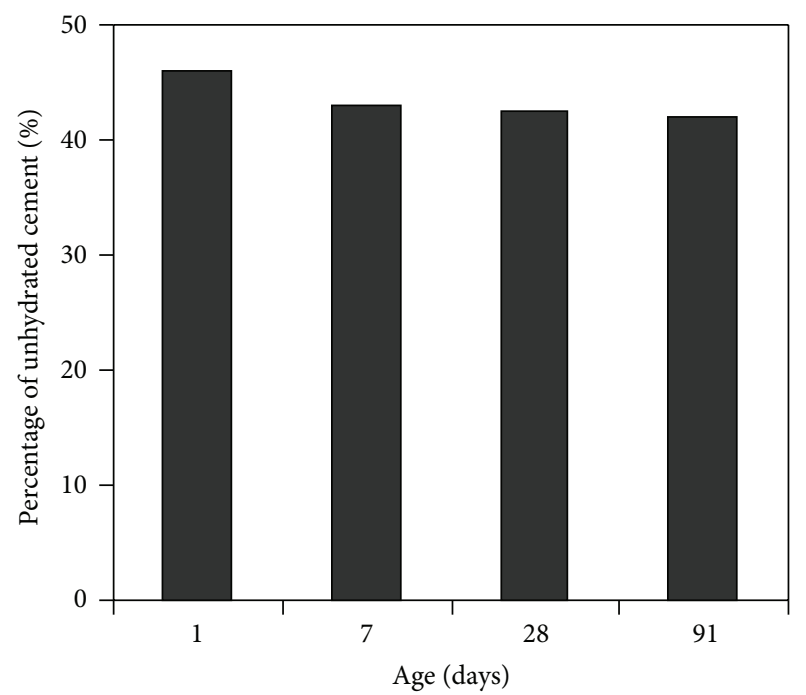

FIGURE 1: The percentage of unhydrated cement in paste (water to binder ratio: 0.18; sand to binder ratio: 1.0; superplasticizer, solid\% by weight of binder: 0.9) [29].

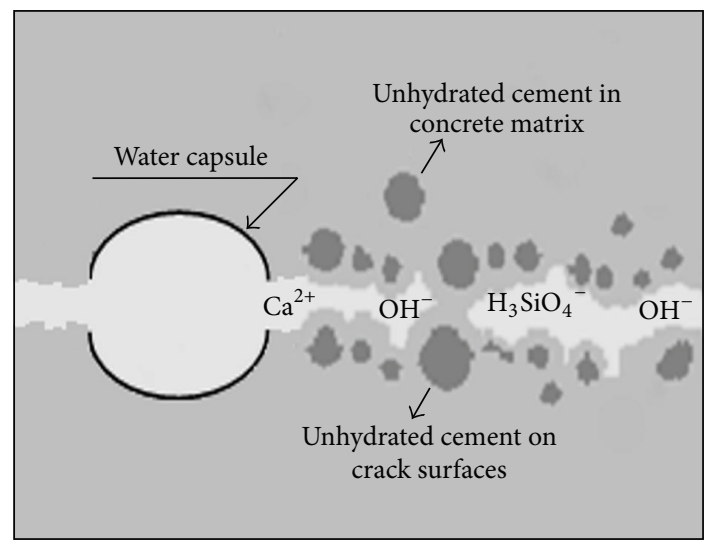

FIgURE 2: Schematic diagram of further hydration [31].

the crack from the unhydrated cement embedded inside the concrete matrix (not on the crack surfaces). These ions also facilitate the formation of healing products in the crack.

What should be mentioned is that the released water in cracks will be absorbed by the concrete matrix due to capillary action. Therefore, the section of crack filled with water will decrease. However, the fact is that the precipitation of further hydration products only takes place in the section of cracks filled with water. When the water in the cracks is absorbed entirely, further hydration in cracks will stop.

2.2. Simulation of Self-Healing by Further Hydration. The processes of self-healing by further hydration mentioned above were simulated in previous study [31]. As shown in Figure 3, a crack with the size of $40 \mathrm{~mm}$ (length) $\times 40 \mathrm{~mm}$ (depth) $\times 10 \mu \mathrm{m}$ (width) is supposed to pass through a capsule. Because the hydration products formed in the cement paste with low w/c ratio are very dense, some unhydrated cement particles can be also passed through by the crack. Assuming 


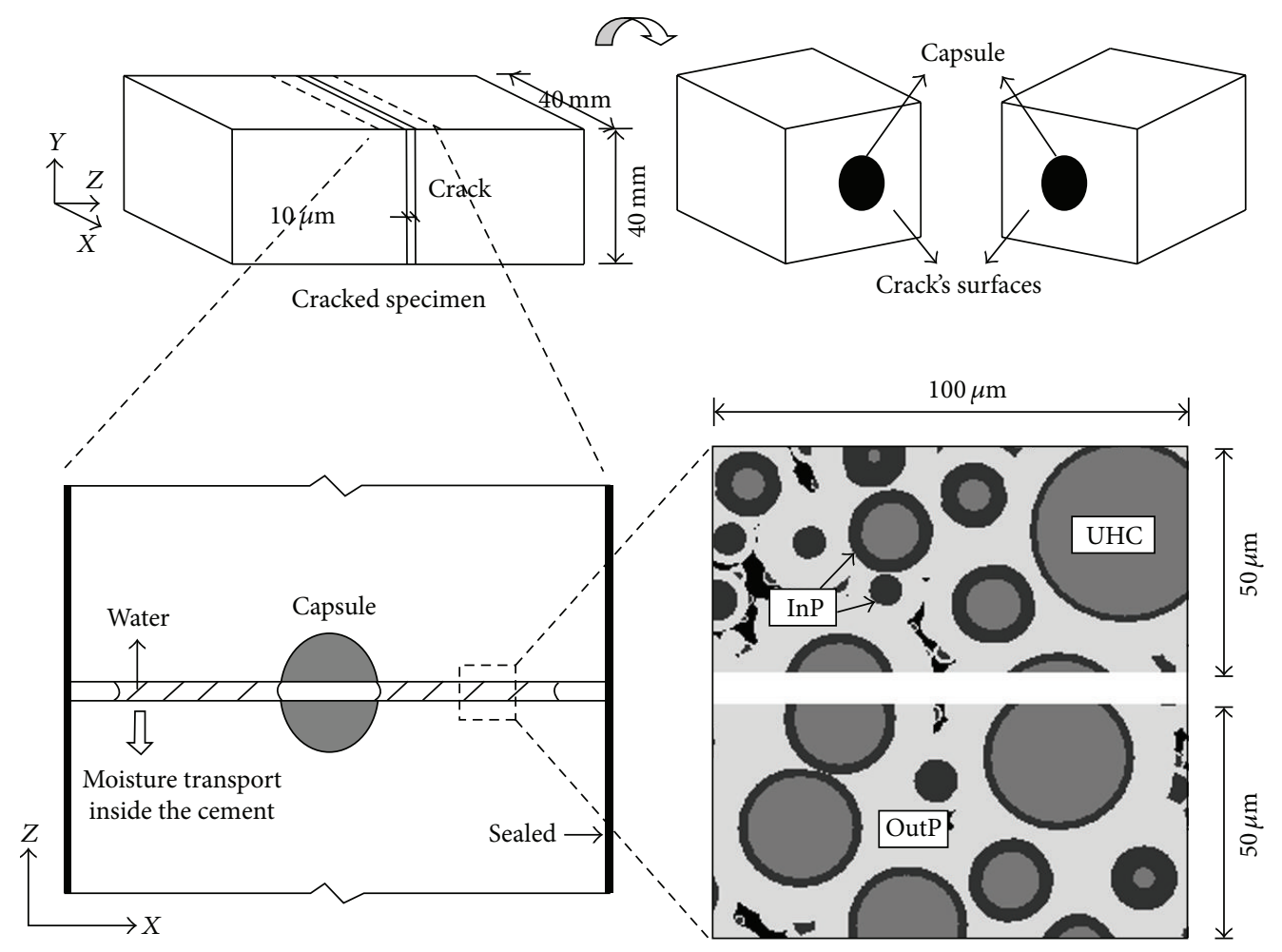

FIGURE 3: Schematic diagram of modeling system for further hydration (InP represents inner products, OutP represents outer products, and UHC represents unhydrated cement particles) [31].

the surrounding surfaces of the cracked specimen are sealed, the water evaporation will not happen and the carbonation of calcite is also prevented.

In the simulation, it was assumed that when the capsules are broken by the crack, all the water stored in the broken capsules can be released into the cracks due to the capillary action. As mentioned, the water in the crack can be absorbed by concrete matrix. The amount of water existing in the crack can be calculated with a water transport model, which is based on mass balance [36-38].

The further hydration processes in water-bearing section of the cracks were simulated in micro level. A tiny square with the size of $100 \mu \mathrm{m} \times 100 \mu \mathrm{m}$ (excluding the crack width) as simulation system from the water-bearing section of crack is shown in Figure 3. The distribution of unhydrated cement particles was simulated by HYMOSTRUC3D [34, 39, 40]. The tiny square was discretized into micropixels with the size of $2 \mu \mathrm{m} \times 2 \mu \mathrm{m}$. The ion concentrations in each micropixel were calculated by the ion diffusion model based on Fick's law. Meanwhile, a thermodynamics model based on chemistry equilibrium, mass balance, and ion charge balance was utilized to simulate the further hydration taking place in the micropixels. At each time step, the ion concentrations calculated by the diffusion model in each micropixel were input into the thermodynamics model. Through the thermodynamics model, the amount of further hydration products was calculated, as well as the ion concentrations after the chemical reaction. The outputs of concentration from the thermodynamics model were input into the diffusion model

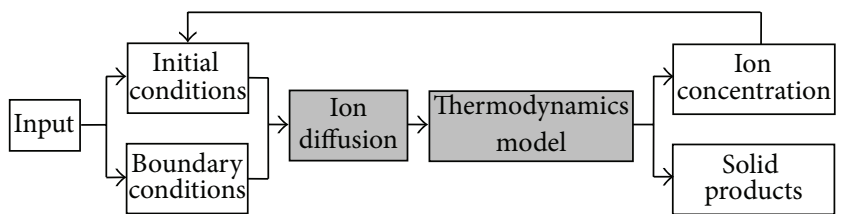

Figure 4: Flowchart of the model for further hydration [31].

again as the initial conditions for the next step of calculation. The condensed flowchart of the model for further hydration is shown in Figure 4.

The self-healing efficiency, defined as the volume ratio of the further hydration products to the crack, can be determined by coupling the water transport and further hydration of cement particles.

\subsection{Self-Healing Efficiency versus Amount of Available Water.} Based on the method in Section 2.2, the relationship between self-healing efficiency and the amount of water released from broken capsules was determined. As shown in Figure 5, selfhealing efficiency rises with the increase of released water at two different slopes. When $100 \mathrm{~mm}^{3}$ of water is provided into the crack, of which the size is $40 \mathrm{~mm}$ (length) $\times 40 \mathrm{~mm}$ (depth) $\times 10 \mu \mathrm{m}$ (width), the final self-healing efficiency is about $9.5 \%$. While the broken capsules provide $150 \mathrm{~mm}^{3}$ of water, the final self-healing efficiency increases to $15.3 \%$. With this slope, the final self-healing efficiency rises to $22.9 \%$ when 


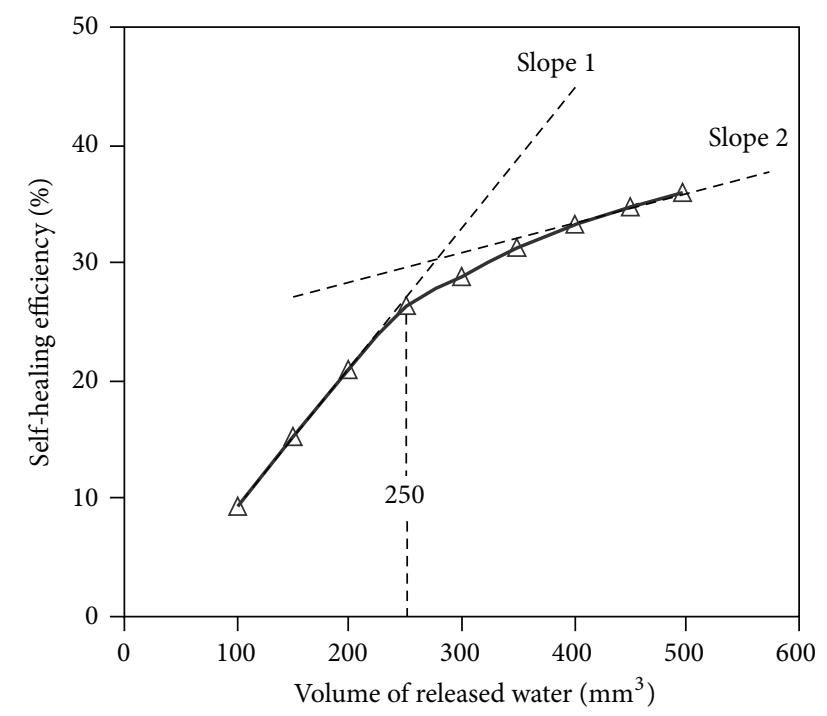

FIGURE 5: Efficiency of self-healing of a crack with the size of $40 \mathrm{~mm}$ (length) $\times 40 \mathrm{~mm}$ (depth) $\times 10 \mu \mathrm{m}$ (width) versus different amount of extra water supplied to the crack via capsules [31].

the extra water increases to $250 \mathrm{~mm}^{3}$. However, the increase of healing efficiency becomes less significant after this point (the slope of this curve is decreasing). The reason is that when the released water contacts with the unhydrated cement on the crack surfaces, further hydration products increase dramatically. Along with the further hydration products formed around the unhydrated cement, further hydration slows down gradually.

\section{Probability of a Crack Hitting Capsules}

As discussed in Section 2, self-healing efficiency depends on the amount of released water from the broken capsules. In the simulation, it is assumed that the capsules can be broken when they are hit by the crack. It is easy to imagine that only some parts of capsules are hit by cracks since the capsules randomly distribute in the whole structure. The hitting probability is dominated by the dosage, the size, and the shape of capsules. By now, there are several analytical models $[41,42]$ for calculating the probability of a crack hitting capsules. In this study, random experiments with the help of computers were performed to calculate the probability of a crack hitting capsules. The effect of capsule size was also taken into account. All the capsules are supposed to be sphere.

\subsection{Method for Calculating the Probability of a Crack Hitting} Capsules. Corresponding to the simulation in Section 2, the modeling system here is a beam with the size of $40 \mathrm{~mm} \times$ $40 \mathrm{~mm} \times 160 \mathrm{~mm}$. As shown in Figure 6, all capsules with identical radius are uniformly dispersed inside the beam and do not overlap or contact with each other. In addition, the capsules can not cross with the surfaces of the beam.

In this study, the cement paste is simplified as homogeneous material. Capsules are assumed to be intersected if they were hit by cracks. In this case, the crack is planar and can be simplified as a plane. Therefore, the hitting probability is equal to the probability of the capsules' centers dispersing inside the "influence zone" of the planar crack, which is shown in Figure 6(b). To obtain the probability of capsules centers dispersing inside the "influence zone" of the planar crack, 1000 random experiments were carried out. Statistical analysis on the amount of capsules passed through by the planar crack was performed. According to the statistical analysis, 1000 experiments can guarantee that the average amount of capsules hit by the crack is within $10 \%$ of the true value in a $95 \%$ degree of confidence.

3.2. Results and Discussion. The probability of the planar crack hitting different amounts of capsules is shown in Figure 7 . When the dosage of capsules is $5 \%$ and the diameter of the capsules is $5 \mathrm{~mm}$, the probability is 1 for the event that $0.5 \%$ of the capsules in the sample are hit by the crack. When the fraction of capsules broken by the crack increases, the corresponding probability decreases. It is impossible for the crack to break all the capsules mixed in the sample. As shown in Figure 7, the probability is almost 0 for the event that more than $6 \%$ of the capsules in the sample are hit by the planar crack. In other cases of diameter, the hitting probability varies in similar tendency.

As mentioned before, because of the low strength of the capsules, the capsules are assumed to be broken when they are hit by the crack and the water is released into the crack from the broken capsules. The amount of released water, corresponding to different dosage of capsules, is shown in Figure 8. For this calculation, the degree of confidence is $95 \%$ (the probability is 0.95 ). It is found that the amount of released water is influenced by the size of capsules. When the size of capsules is small enough, that is, $1.5 \mathrm{~mm}$ and $3 \mathrm{~mm}$, the amount of released water linearly increases with the increase of capsules. This increasing tendency varies when the size of capsules ranges from $5 \mathrm{~mm}$ to $7.5 \mathrm{~mm}$. From Figure 8, it can be learned that, concerning the maximum amount of released water, there is an optimizing size of capsules in each case of dosage of capsules. For example, the optimizing size of capsules is $3.0 \mathrm{~mm}$ when the dosage of capsules is $1 \%$. In comparison, the optimizing size of capsules increases to $6.5 \mathrm{~mm}$ while the dosage of capsules in the sample is $3 \%, 5 \%$, and $7 \%$, respectively. This suggestion is also demonstrated in Figure 9. When the dosage of capsules mixed in the sample is $5 \%$, the fraction of broken capsules varies with the size of capsules while the probability is at the same level. In this study, the degree of confidence is expected to be $95 \%$, which means that the probability of the event should be 0.95 . With this probability, the fraction of capsules broken by the crack ranges from $0.84 \%$ to $2.3 \%$ when the diameter of capsules changes from $1.5 \mathrm{~mm}$ to $7.5 \mathrm{~mm}$. What should be mentioned is that when the size of capsules is $6.5 \mathrm{~mm}$, the amount of broken capsules is the largest.

From this modeling, the amount of released water as the function of the dosage of capsules premixed is determined, which is essential for self-healing efficiency by further hydration. Moreover, the optimizing capsule sizes for different dosage of capsules premixed are suggested. This optimization 


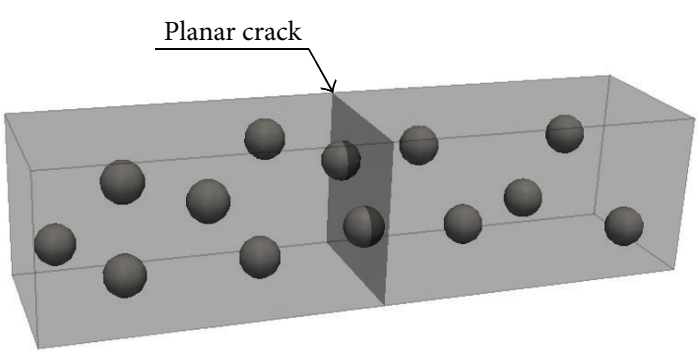

(a)

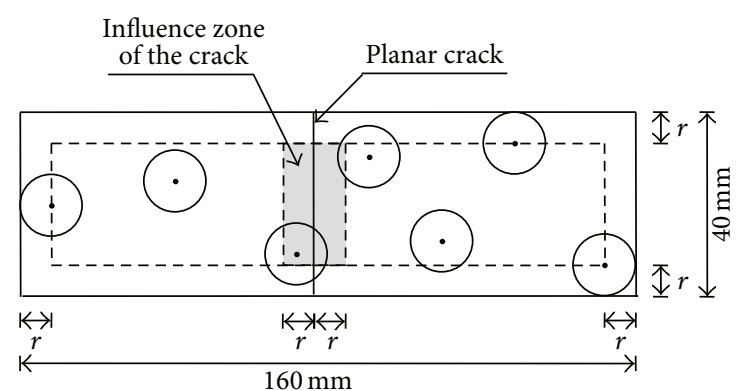

(b)

FIGURE 6: Schematic diagram of a planar crack hitting capsules (a). Planform for the capsule distribution in the sample and the influence zone of the planar crack (b).

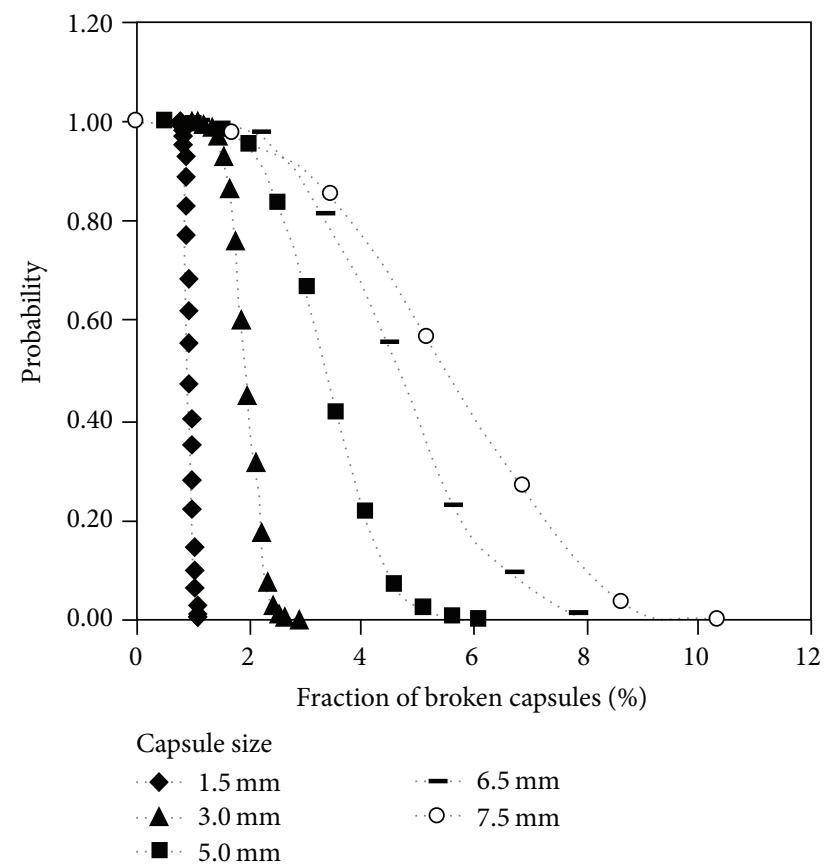

FIGURE 7: Probability of a crack hitting capsules with different size (the dosage of capsules is $5 \%$ ).

on capsule size can significantly improve self-healing of cracks by further hydration in cementitious materials.

\section{The Effects of Capsules on Mechanical Properties}

As mentioned before, since the strength of the capsules is low, the mechanical properties of the structures decrease when some capsules are embedded in the cement matrix. The more the capsules mixed, the lower the mechanical properties. Therefore, the quantified relationship between the mechanical properties and the amount of capsules mixed with cement is essential for the optimization of self-healing. In this section, a 3D lattice model was used to simulate the fracture of the cement paste with capsules.

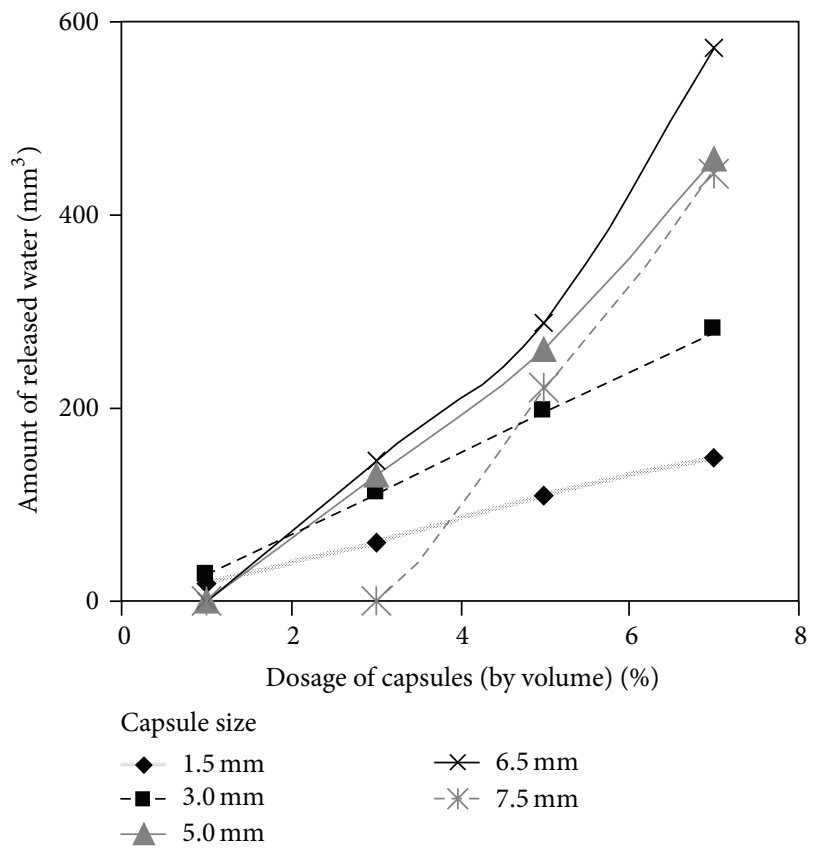

FIGURE 8: Amount of water released from broken capsule with different size (the degree of confidence is $95 \%$ ).

\subsection{D Lattice Model}

4.1.1. Basics of the Model. Lattice model was proposed to describe a material on a macro scale by means of a network of truss elements in 1941 [43]. However, the network of truss elements can not describe the rotation of material in crack face bridge, which usually occurs during the fracture process of concrete [44]. A lattice model with beam elements was proposed by Schlangen and van Mier [32, 45-47]. A triangular shape of lattice is shown in Figure 10(a). The beam elements have fixed connections in the nodes, which can transfer axial force, shear force, and bending moments, as shown in Figure 10(b). The beam is supposed to behave linearly under tensile stress, which is shown in Figure 10(c). In the simulation, first the stress in the beam elements should 


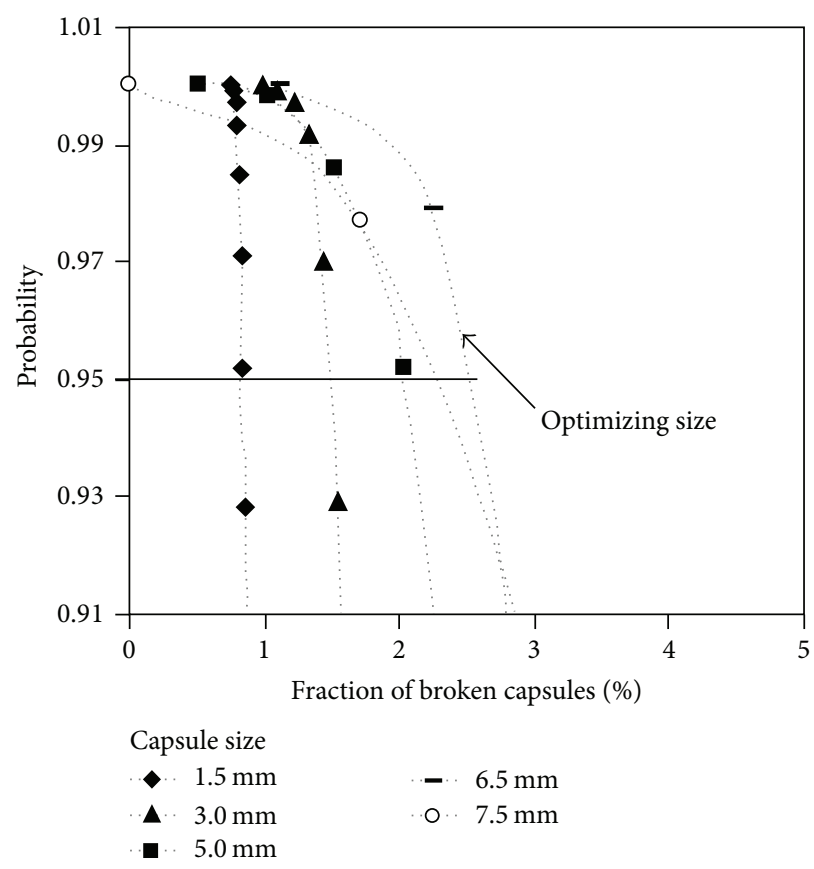

FIGURE 9: Probability of a crack hitting capsules with different size (volume fraction of capsules mixed: 5\%).

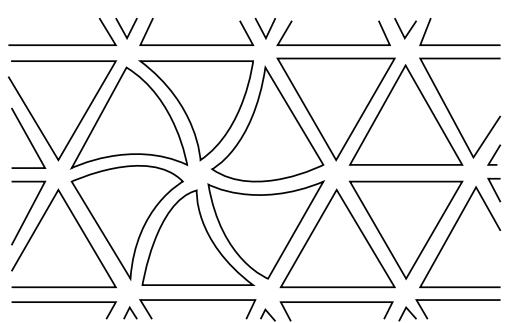

(a)

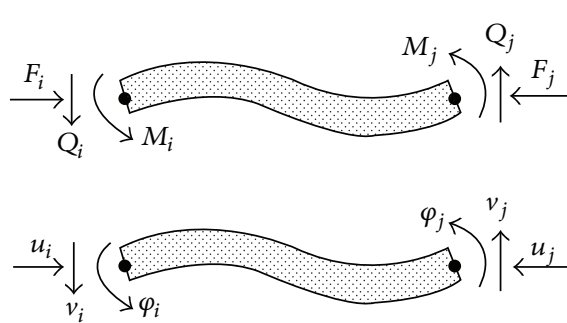

(b)

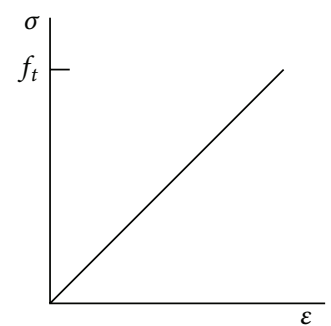

(c)

FIGURE 10: Triangular lattice of beam elements (a); external forces on a single beam element (b); stress-strain relation of a single beam element (c). After Schlangen [32].

be analyzed. The tensile stress of the beam elements can be calculated by the following formula:

$$
\sigma_{t}=\frac{N}{A}+\alpha \cdot \frac{\left(\left|M_{i}\right|,\left|M_{j}\right|\right)_{\max }}{W},
$$

where $N$ is the normal force, $\left|M_{i}\right|\left|M_{j}\right|$ refer to the bending moments in nodes $i$ and $j$, respectively, $A=b \times h$, which represents the cross section of the beams and $W=b \cdot h^{2} / 6$, and $\alpha$ is introduced to select a failure mode where it plays either a dominant or a restricted role.

After the stress analysis, fracturing of material takes place by removing the beam element with the highest stress $\sigma_{t}$ relative to its tensile strength $f_{t}$. The stiffness matrix of the removed beam element will be deleted in the next step of calculation. By multiplying the scale factor, the relationship between the reaction and the displacement can be derived. Following this procedure in each step, an exact solution is obtained.
This lattice model was extended to a 3D model by Qian $[33,48]$. In order to obtain more accurate results, the $3 \mathrm{D}$ version of lattice model was used in this research.

4.1.2. Construction of Lattice Beam. In order to investigate the effects of capsules on the mechanical properties of the structures, the fracture processes of standard beams $(40 \mathrm{~mm}$ $\times 40 \mathrm{~mm} \times 160 \mathrm{~mm}$ ) under tensile loading were simulated by $3 \mathrm{D}$ lattice model. As shown in Figure 11, the capsules randomly distribute inside the sample. In this modeling, the cement paste is assumed to be homogeneous. In addition, since the strength of the liquid inside the capsules is much lower than that of cement paste, the capsules are simplified as holes. It means that the capsule shell and the interface transition zone (ITZ) between capsule shell and concrete matrix are ignored. In order to guarantee that capsules can be intersected by cracks, the fracture energies of capsule shell and ITZ must be lower than that of concrete matrix. In addition, the capsule shell usually is thin. Therefore, the 


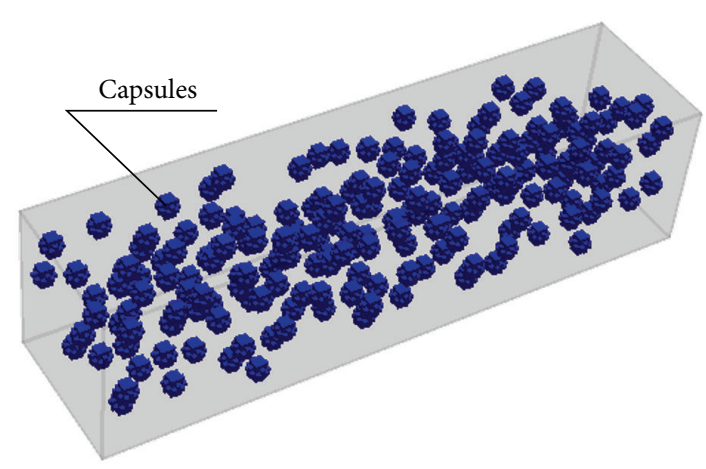

FIGURE 11: Standard beam $(40 \mathrm{~mm} \times 40 \mathrm{~mm} \times 160 \mathrm{~mm})$ containing capsules (the dosage of capsules is $5 \%$ ).

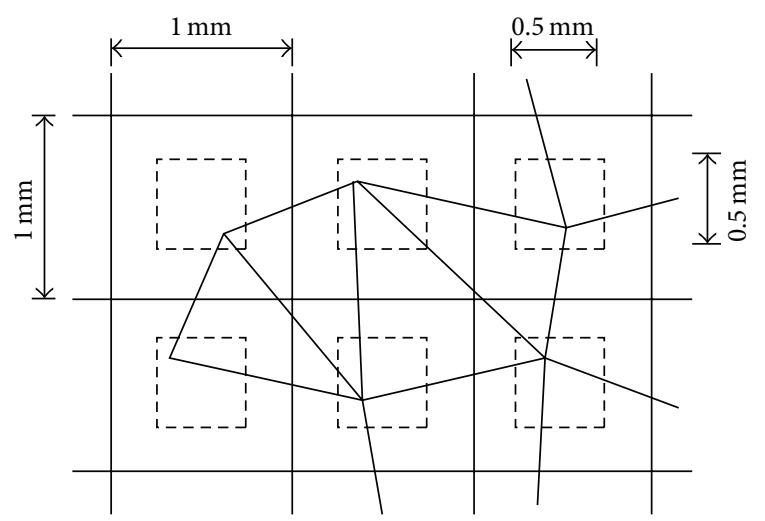

FIGURE 12: Schematic diagram of random lattice from 2D direction. After Schlangen [32].

simplification of capsules as holes has few influences on the calculating strength of concrete with capsules.

Based on these assumptions, the structure of the sample for the lattice model can be generated. This structure for lattice is composed of voxels with the size of $1 \mathrm{~mm} \times 1 \mathrm{~mm} \times$ $1 \mathrm{~mm}$. As shown in Figure 12, a point is selected at random in the smaller cube $(0.5 \mathrm{~mm} \times 0.5 \mathrm{~mm} \times 0.5 \mathrm{~mm})$ in each voxel for cement paste. The random lattice is defined by connecting these points with beam elements. In this way, the disorder of cement paste is implemented by the difference in beam length. The lattice constructed by beam elements for the sample with capsules is shown in Figure 13. The properties of beam elements are assigned according to the properties of cement paste, which are shown in Table 1 [33].

4.2. Results and Discussion. As shown in Figures 14 and 15, the mechanical properties decrease with the increase of capsules mixed in the sample. From Figure 15, it can be found that the decreasing rate of elastic modulus is smaller than that of tensile strength. When the volume of capsules mixed in the sample is $7 \%$, the elastic modulus of the sample drops by almost $17 \%$, while the tensile strength decreases by more than $50 \%$. For the tensile strength, the tendency of decrease is most obvious when the volume fraction of capsules ranges from $0 \%$ to $3 \%$.

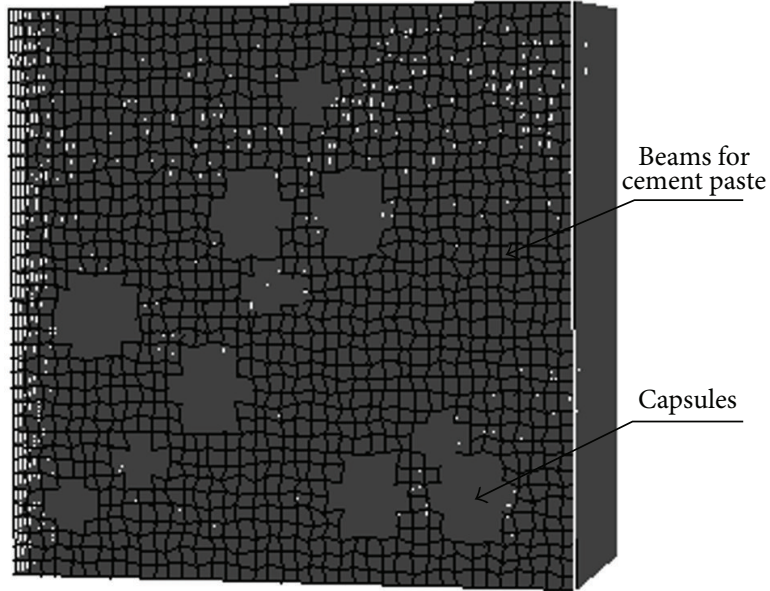

FIGURE 13: Cross section of the lattice constructed by beam elements for the sample with capsules.

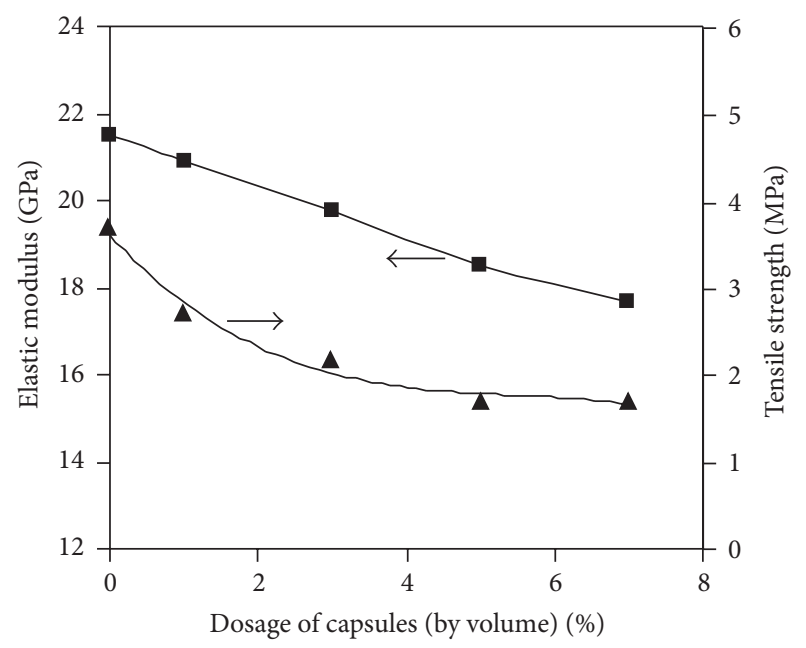

Figure 14: The elastic modulus and tensile strength of the samples with different amount of capsules.

From these results, it can be learned that the negative effects of capsules on the mechanical properties are significant, especially for the tensile strength. These negative effects should be taken into account while designing the mixture of cementitious materials with self-healing capacity.

\section{Analysis on the Dosage of Capsules}

Based on Figures 5 and 8, the relationship between selfhealing efficiency and the dosage of capsules with different size can be determined, which is shown in Figure 16. It is clear that the self-healing efficiency increases with the increase of capsules. As discussed in Section 3.2, the amount of water released from the broken capsules is the largest when the diameter of capsules is $6.5 \mathrm{~mm}$ (the dosage of capsules is more than $3 \%$ ). Therefore, as shown in Figure 16, the self-healing efficiency is the highest when the capsules size is $6.5 \mathrm{~mm}$ and the dosage of capsules is more than $3 \%$. 
TABLE 1: Mechanical properties of cement paste [33].

\begin{tabular}{lccc}
\hline Tensile strength $(\mathrm{MPa})$ & Compressive strength $(\mathrm{MPa})$ & Elastic modulus $(\mathrm{GPa})$ & Elastic shear modulus $(\mathrm{GPa})$ \\
\hline 4.7 & 120 & 23 & 11
\end{tabular}

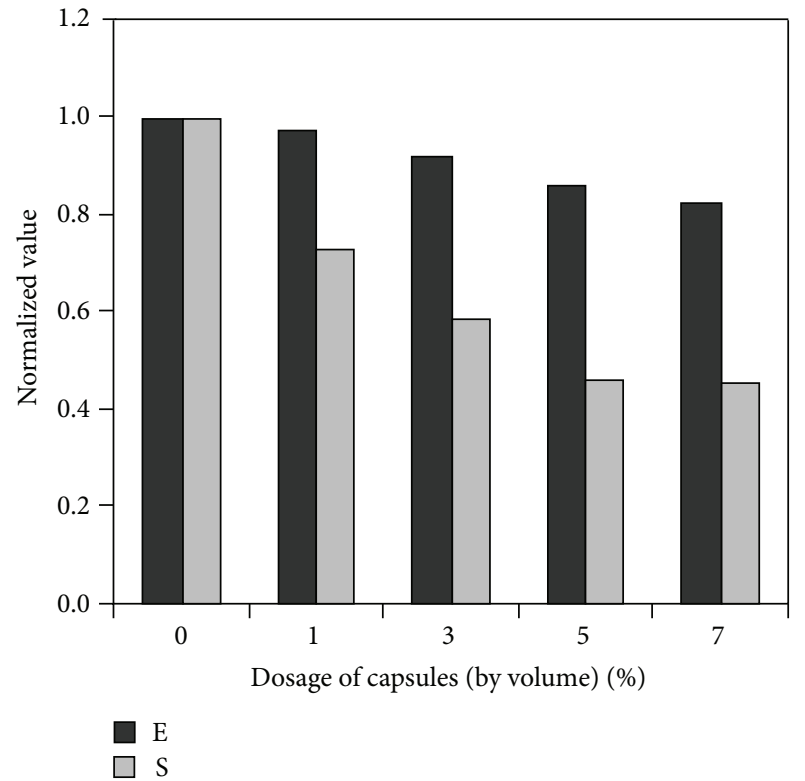

FIGURE 15: The decrease of mechanical properties with the increase of capsules (E: elastic modulus; S: tensile strength).

However, as mentioned in Section 4.2, the mechanical properties decrease with the increase of capsules mixed in the sample. Figure 17 shows the comparison of self-healing efficiency and the decrease of tensile strength when different amounts of capsules are mixed. In order to compare the positive effects with the negative effects of the capsules, the ratio of self-healing efficiency to the decrease of normalized tensile strength was defined. In this study, the positive effect of the capsules refers to the capacity of inducing self-healing by providing extra water. The negative effect refers to the decrease of mechanical properties caused by the addition of capsules.

For capsule dosage of 3\%, the tensile strength of concrete containing capsules is about 59\% of that without capsules. It can be found that self-healing efficiency increases by $15 \%$ while the tensile strength decreases by $41 \%$, when the dosage of capsules is $3 \%$. Therefore, the ratio of self-healing efficiency to the decrease of tensile strength is about 0.36 . This ratio increases to 0.70 , when the dosage of capsules rises to $7 \%$. It means that the increase of positive effect of the capsules is larger than that of the negative effect when the dosage of capsules goes up.

However, it is obvious that the decrease of more than $30 \%$ of the tensile strength is too much for the engineering practice. Therefore, strategies such as increasing reinforced bars or fibers in the mixture should be proposed while applying capsules to realize self-healing in cementitious materials.

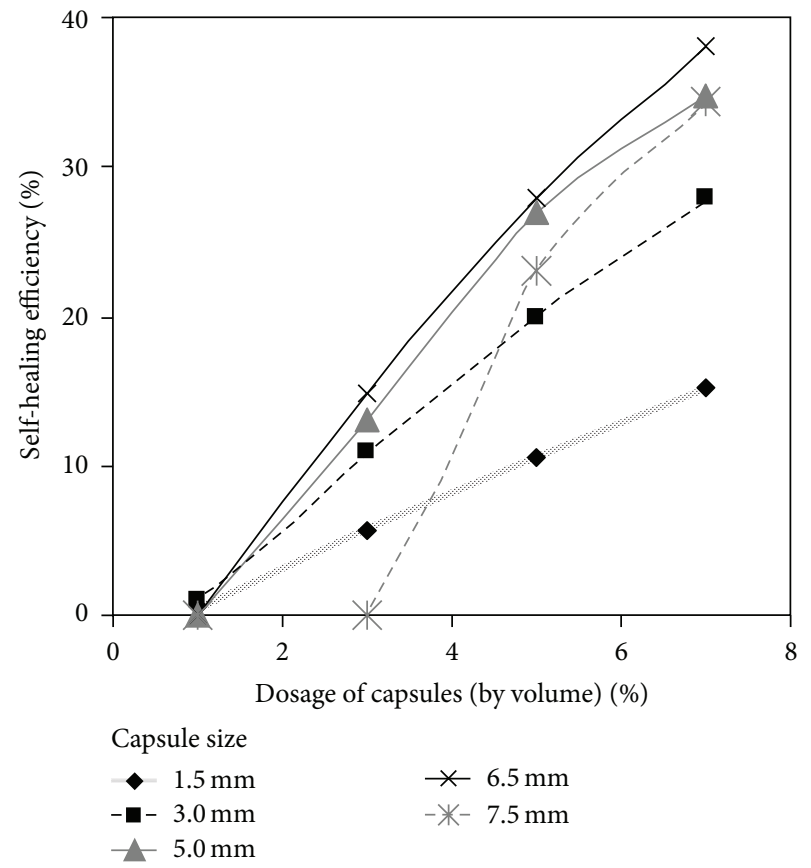

FIGURE 16: The self-healing efficiency with different amount of capsules.

\section{Conclusions}

The effects of the dosage and size of capsules on self-healing and mechanical properties in cementitious materials were investigated in this paper. The probability of a crack hitting capsules was determined by performing random experiments with the help of computers. In this way, the relationship between the amount of released water and the dosage of capsules was determined. The effects of the capsule size on the amount of released water were also explored. By knowing the amount of water supplied via capsules, the efficiency of selfhealing due to further hydration of unhydrated cement was quantified by modeling. In addition, the impact of capsules on mechanical properties was investigated numerically.

From the results, it can be learned that the increase rate of the amount of released water to the dosage of capsules changes with the size of capsules. Concerning the maximum amount of released water, the optimizing size of capsules is $6.5 \mathrm{~mm}$ while the dosage of capsules is $3 \%, 5 \%$, and $7 \%$, respectively. Based on the relationship between selfhealing efficiency and the amount of released water from the broken capsules, self-healing efficiency as the function of the dosage of capsules was determined. Regarding the mechanical properties, both elastic modulus and tensile strength of the samples decrease with the increase of capsule. The decreasing tendency of tensile strength is larger than that of elastic modulus. Comparing the effects of capsules 


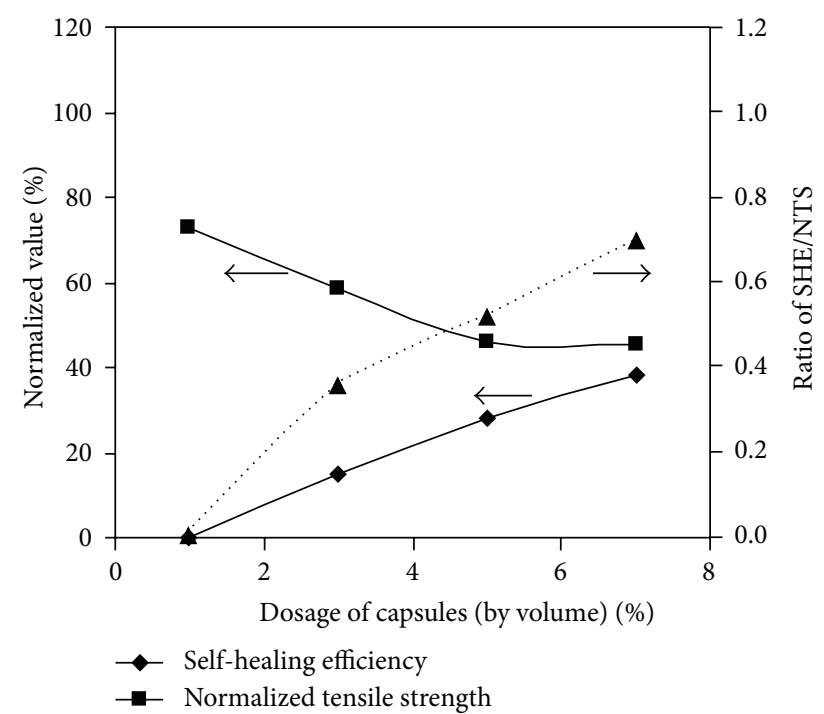

FIGURE 17: Comparison of self-healing efficiency and decrease of tensile strength (SHE/DTS is the ratio of self-healing efficiency to the decrease of normalized tensile strength). The triangles and the dotted curve refer to ratio of SHE/NTS of the vertical axis on the right side.

on self-healing with that on mechanical properties, it can be found that the increase of positive effect (the capacity of inducing self-healing) of capsules is larger than that of negative effects (decreasing mechanical properties) when the dosage of capsules increases. However, the negative effects of capsules on mechanical properties are not ignored. It must be emphasized that self-healing based on mineral admixtures and bacteria proceeds faster than self-healing due to further hydration of unhydrated cement $[15,18,23]$. Therefore, the efficiency of self-healing based on mineral admixtures and bacteria should be higher than that of self-healing due to further hydration of unhydrated cement when the dosages and sizes of capsules are the same.

\section{Competing Interests}

The authors declare that they have no competing interests.

\section{Acknowledgments}

The authors would like to thank the "Nature Science Fund of Jiangsu” (BK20150601), "Fundamental Research Funds for the Central Universities" (2242016K40014), and the "Open Fund of State Key Laboratory of High Performance Civil Engineering Materials" (2015CEM002) for the financial support. Prof. Erik Schlangen and Dr. Zhiwei Qian are highly appreciated for their help with the use of 3D Lattice Model.

\section{References}

[1] K. van Breugel, "Is there a market for self-healing cement-based materials?" in Proceedings of the 1st International Conference on Self-Healing Materials, Noordwijk, The Netherlands, 2007.
[2] M. de Rooij, K. van Tittelboom, N. De Belie, and E. Schlangen, Eds., Self-Healing Phenomena in Cement-Based Materials: Stateof-the-Art Report of RILEM Technical Committee 221-SHC: SelfHealing Phenomena in Cement-Based Materials, Springer, New York, NY, USA, 2013.

[3] C. Edvardsen, "Water permeability and autogenous healing of cracks in concrete," ACI Materials Journal, vol. 96, no. 4, pp. 448-454, 1999.

[4] H.-W. Reinhardt and M. Jooss, "Permeability and self-healing of cracked concrete as a function of temperature and crack width," Cement and Concrete Research, vol. 33, no. 7, pp. 981-985, 2003.

[5] S. Granger, A. Loukili, G. Pijaudier-Cabot, and G. Chanvillard, "Experimental characterization of the self-healing of cracks in an ultra high performance cementitious material: mechanical tests and acoustic emission analysis," Cement and Concrete Research, vol. 37, no. 4, pp. 519-527, 2007.

[6] D. Homma, H. Mihashi, and T. Nishiwaki, "Self-healing capability of fibre reinforced cementitious composites," Journal of Advanced Concrete Technology, vol. 7, no. 2, pp. 217-228, 2009.

[7] Y. Yang, M. D. Lepech, E.-H. Yang, and V. C. Li, "Autogenous healing of engineered cementitious composites under wet-dry cycles," Cement and Concrete Research, vol. 39, no. 5, pp. 382390, 2009.

[8] S. Granger, G. Pijaudier Cabot, A. Loukili, D. Marlot, and J. C. Lenain, "Monitoring of cracking and healing in an ultra high performance cementitious material using the time reversal technique," Cement and Concrete Research, vol. 39, no. 4, pp. 296-302, 2009.

[9] H. Huang, G. Ye, C. Qian, and E. Schlangen, "Self-healing in cementitious materials: materials, methods and service conditions," Materials \& Design, vol. 92, pp. 499-511, 2016.

[10] V. C. Li and E. Herbert, "Robust self-healing concrete for sustainable infrastructure," Journal of Advanced Concrete Technology, vol. 10, no. 6, pp. 207-218, 2012.

[11] B. Dong, Y. Wang, G. Fang, N. Han, F. Xing, and Y. Lu, "Smart releasing behavior of a chemical self-healing microcapsule in the stimulated concrete pore solution," Cement and Concrete Composites, vol. 56, pp. 46-50, 2015.

[12] B. Hilloulin, K. Van Tittelboom, E. Gruyaert, N. De Belie, and A. Loukili, "Design of polymeric capsules for self-healing concrete," Cement and Concrete Composites, vol. 55, pp. 298307, 2015.

[13] K. Van Tittelboom, N. De Belie, D. Van Loo, and P. Jacobs, "Self-healing efficiency of cementitious materials containing tubular capsules filled with healing agent," Cement and Concrete Composites, vol. 33, no. 4, pp. 497-505, 2011.

[14] T.-H. Ahn and T. Kishi, "Crack self-healing behavior of cementitious composites incorporating various mineral admixtures," Journal of Advanced Concrete Technology, vol. 8, no. 2, pp. 171186, 2010.

[15] M. Roig-Flores, S. Moscato, P. Serna, and L. Ferrara, "Selfhealing capability of concrete with crystalline admixtures in different environments," Construction and Building Materials, vol. 86, pp. 1-11, 2015.

[16] Y.-S. Lee and J.-S. Ryou, "Self healing behavior for crack closing of expansive agent via granulation/film coating method," Construction and Building Materials, vol. 71, pp. 188-193, 2014.

[17] C. Stuckrath, R. Serpell, L. M. Valenzuela, and M. Lopez, "Quantification of chemical and biological calcium carbonate precipitation: performance of self-healing in reinforced mortar containing chemical admixtures," Cement and Concrete Composites, vol. 50, pp. 10-15, 2014. 
[18] Z. Jiang, W. Li, and Z. Yuan, "Influence of mineral additives and environmental conditions on the self-healing capabilities of cementitious materials," Cement and Concrete Composites, vol. 57, pp. 116-127, 2015.

[19] K. Sisomphon, O. Copuroglu, and E. A. B. Koenders, "Selfhealing of surface cracks in mortars with expansive additive and crystalline additive," Cement and Concrete Composites, vol. 34, no. 4, pp. 566-574, 2012.

[20] H. M. Jonkers, A. Thijssen, G. Muyzer, O. Copuroglu, and E. Schlangen, "Application of bacteria as self-healing agent for the development of sustainable concrete," Ecological Engineering, vol. 36, no. 2, pp. 230-235, 2010.

[21] V. Wiktor and H. M. Jonkers, "Quantification of crack-healing in novel bacteria-based self-healing concrete," Cement and Concrete Composites, vol. 33, no. 7, pp. 763-770, 2011.

[22] M. Luo, C.-X. Qian, and R.-Y. Li, "Factors affecting crack repairing capacity of bacteria-based self-healing concrete," Construction and Building Materials, vol. 87, pp. 1-7, 2015.

[23] J. Y. Wang, H. Soens, W. Verstraete, and N. De Belie, "Selfhealing concrete by use of microencapsulated bacterial spores," Cement and Concrete Research, vol. 56, pp. 139-152, 2014.

[24] J. Xu and W. Yao, "Multiscale mechanical quantification of selfhealing concrete incorporating non-ureolytic bacteria-based healing agent," Cement and Concrete Research, vol. 64, pp. 1-10, 2014.

[25] N. Hearn, "Self-sealing, autogenous healing and continued hydration: what is the difference?" Materials and Structures, vol. 31, no. 212, pp. 563-567, 1998.

[26] H. Huang, G. Ye, and L. Pel, "New insights into autogenous selfhealing in cement paste based on nuclear magnetic resonance (NMR) tests," Materials and Structures, vol. 49, no. 7, pp. 25092524, 2016.

[27] H. Huang, G. Ye, and D. Damidot, "Characterization and quantification of self-healing behaviors of microcracks due to further hydration in cement paste," Cement and Concrete Research, vol. 52, pp. 71-81, 2013.

[28] S. Z. Qian, J. Zhou, and E. Schlangen, "Influence of curing condition and precracking time on the self-healing behavior of Engineered Cementitious Composites," Cement and Concrete Composites, vol. 32, no. 9, pp. 686-693, 2010.

[29] N. Van Tuan, G. Ye, K. van Breugel, and O. Copuroglu, "Hydration and microstructure of ultra high performance concrete incorporating rice husk ash," Cement and Concrete Research, vol. 41, no. 11, pp. 1104-1111, 2011.

[30] Z. Yang, J. Hollar, X. He, and X. Shi, "A self-healing cementitious composite using oil core/silica gel shell microcapsules," Cement and Concrete Composites, vol. 33, no. 4, pp. 506-512, 2011.

[31] H. Huang and G. Ye, "Simulation of self-healing by further hydration in cementitious materials," Cement and Concrete Composites, vol. 34, no. 4, pp. 460-467, 2012.

[32] E. Schlangen, Experimental and Numerical Analysis of Fracture Processes in Concrete, Delft University of Technology, Delft, Netherlands, 1993.

[33] Z. Qian, Multiscale Modeling of Fracture Processes in Cementitious Materials, Delft University of Technology, 2012.

[34] K. van Breugel, Simulation of Hydration and Formation of Structure in Hardening Cement-Based Materials, Delft University of Technology, Delft, Netherlands, 1991.

[35] H. F. W. Taylor, Cement Chemistry, Thomas Telford Publishing, London, UK, 1997.
[36] K. Maekawa, R. Chaube, and T. Kishi, Modeling of Concrete Performance: Hydration, Microstructure and Mass Transport, E \& FN Spon, London, UK, 1999.

[37] R. Cerny and P. Rovnanikova, Transport Process in Concrete, Taylor \& Francis, London, UK, 2002.

[38] H. Huang, G. Ye, and K. Van Breugel, "Numerical simulation on moisture transport in cracked cement-based materials in view of self-healing of crack," Journal Wuhan University of Technology, Materials Science Edition, vol. 25, no. 6, pp. 10771081, 2010.

[39] E. A. B. Koenders, Simulation of Volume Changes in Hardening Cement-Based Materials, Delft University of Technology, 1997.

[40] G. Ye, Experimental Study and Numerical Simulation of the Development of the Microstructure and Permeability of Cementitious Materials, Delft University of Technology, Delft, The Netherlands, 2003.

[41] Z. Lv, H. Chen, and H. Yuan, "Quantitative solution on dosage of repair-agent for healing of 3D simplified cracks in materials: short capsule model," Materials and Structures, vol. 44, no. 5, pp. 987-995, 2011.

[42] S. V. Zemskov, H. M. Jonkers, and F. J. Vermolen, “Two analytical models for the probability characteristics of a crack hitting encapsulated particles: application to self-healing materials," Computational Materials Science, vol. 50, no. 12, pp. 3323-3333, 2011.

[43] A. Hrennikoff, "Solution of problems of elasticity by the framework method," Journal of Applied Mechanics, vol. 8, pp. 169-175, 1941.

[44] J. G. M. van Mier, "Mode I fracture of concrete: discontinuous crack growth and crack interface grain bridging," Cement and Concrete Research, vol. 21, no. 1, pp. 1-15, 1991.

[45] E. Schlangen and E. J. Garboczi, "Fracture simulations of concrete using lattice models: computational aspects," Engineering Fracture Mechanics, vol. 57, no. 2-3, pp. 319-332, 1997.

[46] E. Schlangen and J. G. M. van Mier, "Simple lattice model for numerical simulation of fracture of concrete materials and structures," Materials and Structures, vol. 25, no. 9, pp. 534-542, 1992.

[47] E. Schlangen and J. G. M. van Mier, "Experimental and numerical analysis of micromechanisms of fracture of cementbased composites," Cement and Concrete Composites, vol. 14, no. 2, pp. 105-118, 1992.

[48] Z. Qian, 3D Lattice Analysis of Cement Paste, Delft University of Technology, 2008. 

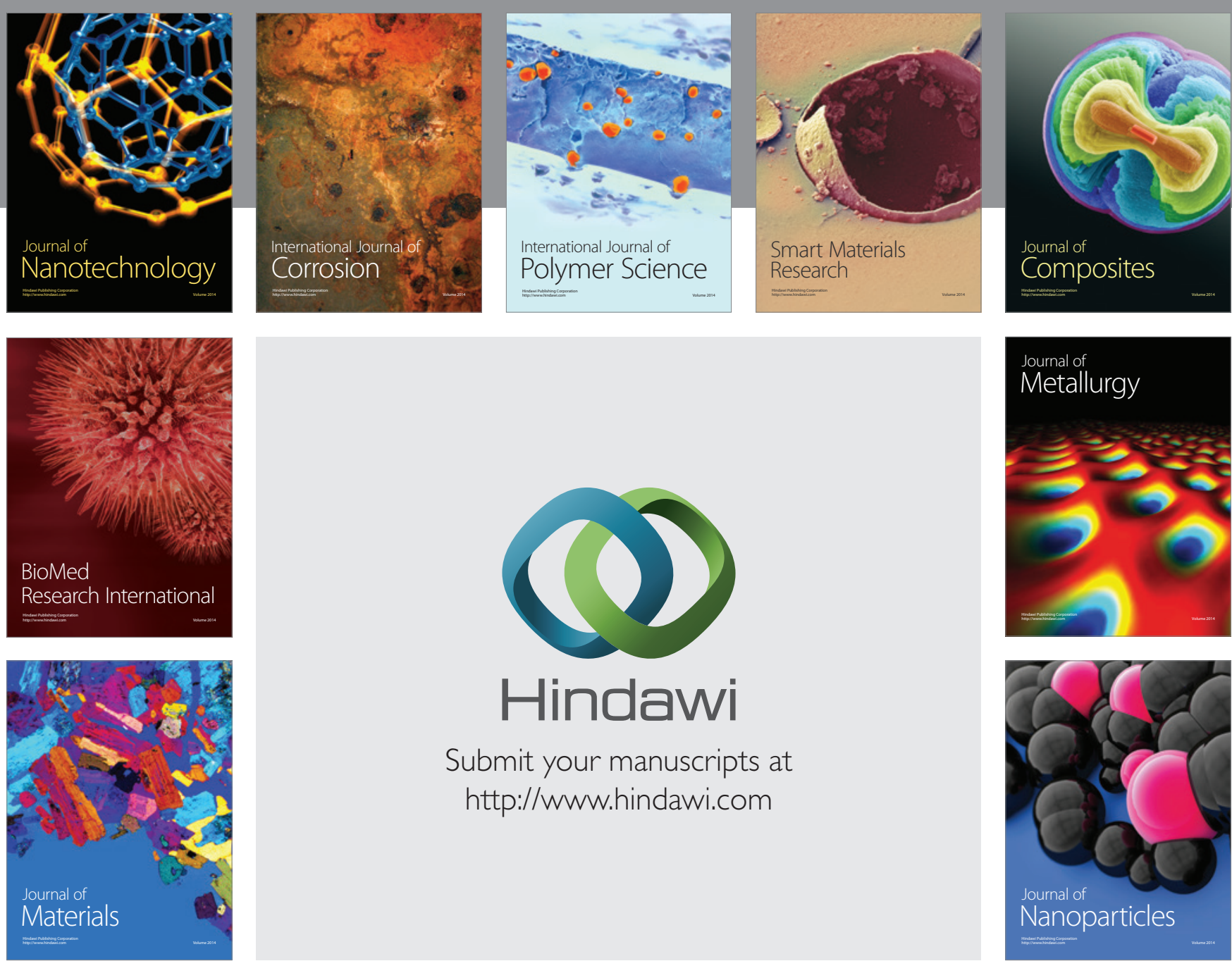

\section{Hindawi}

Submit your manuscripts at

http://www.hindawi.com

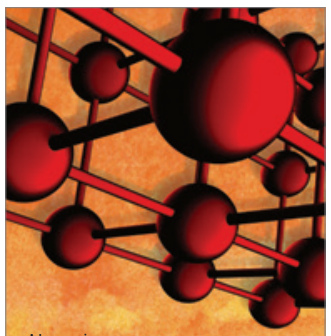

Materials Science and Engineering
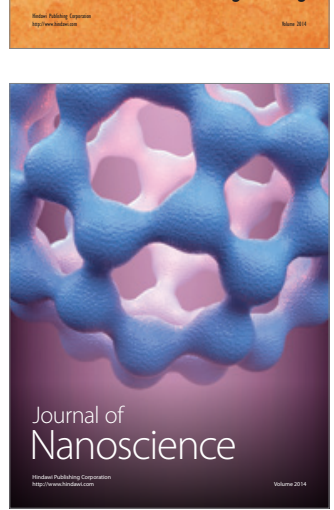
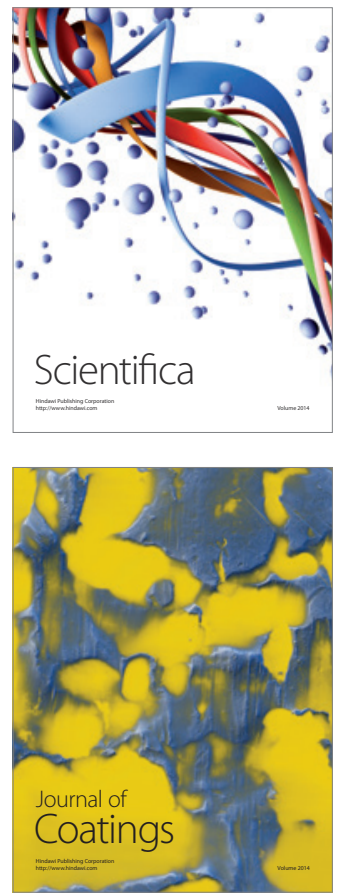
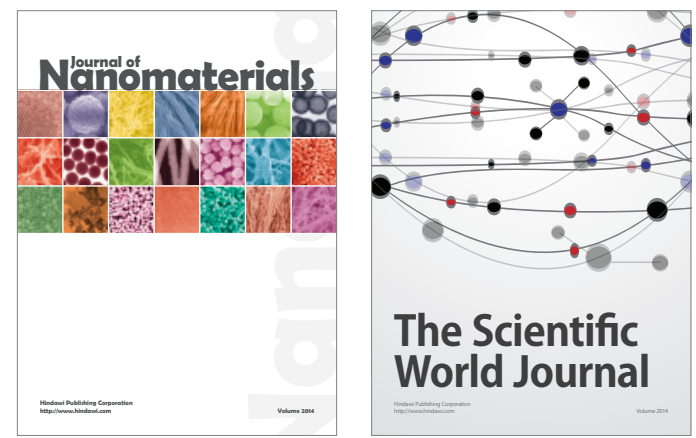

The Scientific World Journal
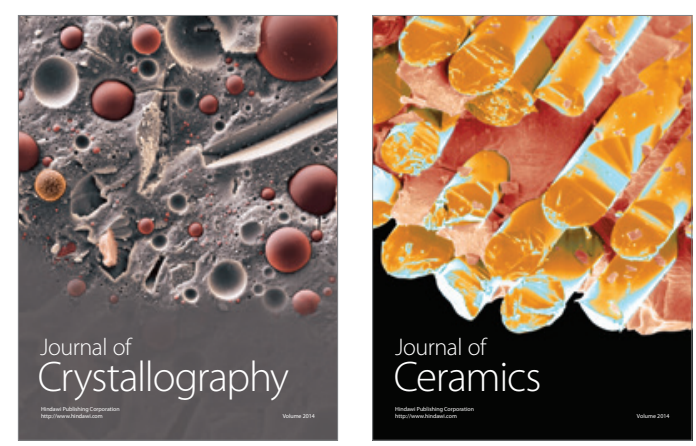
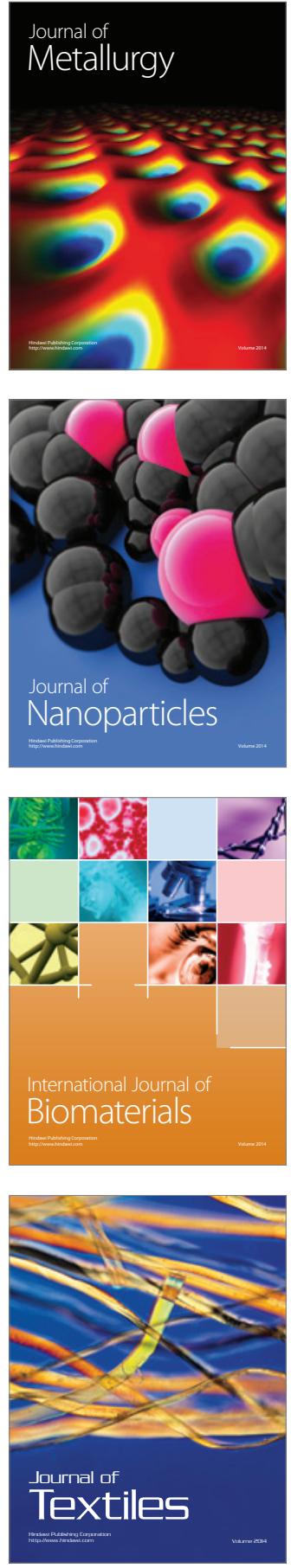